\title{
Rhetorical Structure of Thesis Introduction Chapters Written By English Native Speakers
}

\author{
Sri Wuli Fitriati ${ }^{1}$, Wawan Gunawan ${ }^{2}$, Alief Noor Farida ${ }^{3}$, Nurjannah Mutiara Gayatri ${ }^{4}$ \\ \{SriWuli.Fitriati@mail.unnes.ac.id ${ }^{1}$,wagoen@upi.edu ${ }^{2}$, \\ aliefnoorfarida@mail.unnes.ac.id ${ }^{3}$ \} \\ English Department, Universitas Negeri Semarang ${ }^{1}$, English Department, Universitas \\ Pendidikan Indonesia ${ }^{2}$, English Department, Universitas Negeri Semarang ${ }^{3}$ \\ Semarang, Indonesia
}

\begin{abstract}
Thesis introduction chapters provide readers with the description of a research topic as well as the importance of conducting the research. The quality of thesis introduction chapters is highly affected by their rhetorical structure, which is manifested through particular moves and steps in developing paragraphs. Previous studies confirmed that native English speakers tend to demonstrate particular rhetorical structures in composing their thesis introduction. This paper is part of a larger study on investigating the introduction chapters of theses. By employing a qualitative discourse study, five introduction chapters of theses in the field of English language education and Applied Linguistics written by English native speaker students of Master's program abroad were analyzed. The data were analysed by adopting Swales' CARS framework (2004) to yield a description of the rhetorical structures of the thesis introduction chapters. This study will contribute to facilitating the teaching of academic writing by providing the generic structures of a good model of thesis introduction chapters generated from the findings of the present study.
\end{abstract}

Keywords: move analysis, rhetorical structure, thesis introduction

\section{Introduction}

An introduction chapter provides a key role to the quality of the study as a whole as it serves to establish a territory, a niche, and occupying the niche. As to ensure the role of introduction chapter, currently, there has been a wide interest in genre-based study or genre analysis. Genre analysis refers to an area of analysis which is aimed at revealing rhetorical structures of spoken or written discourse. The term rhetorical structures is considered equivalent with structural patterns, rhetorical patterns, structural organisation, rhetorical organization, and rhetorical strategies. Rhetorical structures are becoming a great concern in composing introduction chapters as it is highly associated with communicative functions of the introduction chapters.Studies focusing on rhetorical structures of introduction chapters have been investigated by worldwide researchers [1]; [2]; [3]; [4]; [5]; [6]; [7]; [8]; [9]. [9] investigated generic structure of introduction in research articles written by L1 Chinese student writers versus L1 
English published writers. The findings claimed that English native speakers employed more various steps than the Chinese student writers, especially in Move 1 "establishing a territory" and Move 2 "establishing a niche". [4] examined rhetorical structure in thesis introductions written by Indonesian postgraduate students by identifying the Moves and Steps. The analysis results revealed that the introduction chapters are realized through three Moves and fifteen Steps as suggested in Bunton's model. Moreover, the results revealed three newly identified steps. This study concluded that the majority of Indonesian postgraduate students tend to develop thesis introductions by justifying the gap found in the previous studies. [2] investigated and compared rhetorical structure in thesis introductions written by Philippine students and American students. This study figured out that the former category tended to follow common patterns in their introduction, while the latter category demonstrated more free writing style.

As a follow-up investigation, this study attempts to contribute to the existing studies on rhetorical structures of thesis introduction chapters to confirm a conventional way that native speakers of English establish in their thesis introduction chapters. The main research question of this study is how are the rhetorical structures constructed in the thesis introduction chapters written by native English writers in the field of TESOL $\&$ applied linguistics? This research question is broken down into two research questions (1) how are general moves constructed in the thesis introduction chapters? (2) how are constituent steps constructed in the thesis introduction chapters?

This study, hence, aims at analyzing introduction chapters of Master's theses written by native English speakers, as an attempt to search for a model of writing effective introduction of a thesis. Further, the findings of this study are expected to be one of the references in writing a thesis introduction chapter for EFL or EFL novice writers.

\section{Methodology}

The study was a qualitative discourse study by analyzing five introduction chapters of theses in the field of English language education and Applied Linguistics written by English native speaker students of Master's program abroad. The data were selected purposefully as it needs efforts to some extent to get accessed to the full online version of the theses. Moreover, this study makes its scope to theses on applied linguistics or TESOL so it was carefully identified before being taken as the data source. The theses were published during the years 2017 and 2019. The theses were chosen whose contents appear to relate to the field of applied linguistics \& language teaching.

The introduction chapters were then analyzed by adopting revised version of CARS framework by [10] to yield a description of the rhetorical structures of the thesis introduction chapters. CARS framework by [10] used in this study is presented below.

Move 1. Establishing a territory

Step 1. Claiming centrality

Step 2. Making topic generalizations

Step 3. Defining terms

Step 4. Reviewing previous research

Move 2. Establishing a niche

Step 1A. Counter Claiming 
Step 1B. Indicating a gap

Step 1C. Question-Raising

Step 1D. Continuing a Tradition

Move 3. Occupying the niche

Step 1. Purposes, aims, or objectives

Step 2. Work carried out

Step 3. Method

Step 4. Materials or Subjects

Step 5. Findings or Results

Step 6. Product of Research

Step 7. Significance/justification

Step 8. Thesis Structure

Step 9. Research Limitations

\section{Finding and Discussion}

This section will be focusing on two primary findings of this study to explain rhetorical structures in thesis introduction chapters written by English native speakers.

a. Moves in Thesis Introduction Chapters Written by Native Speakers

Each Introduction Chapter displayed a generic pattern, comprising a series of Moves and Steps. The results of Move analysis are shown in Table 1.

Table 1. Moves in Thesis Introduction Chapters Written by Native Speakers

\begin{tabular}{lll}
\hline Moves & f & \% \\
\hline Move 1. Establishing a Territory & 5 & $100 \%$ \\
Move 2. Establishing a Niche & 5 & $100 \%$ \\
Move 3. Occupying the Niche & 5 & $100 \%$ \\
\hline
\end{tabular}

Based on Table 1, English native speakers employed three Moves as suggested in the modified CARS model by [10], i.e. Move 1 (Establishing a Territory), Move 2 (Establishing a Niche), and Move 3 (Occupying the Niche). Move 1 is aimed at introducing a general area of research and accentuating that the research area is problematic, relevant, and important. Move 2 serves to accentuate a particular piece of research as well as why and how this particular piece of research is worth investigating. Furthermore, Move 3 points out the means by which the current study can contribute to the existing knowledge and the prior research.

The $100 \%$ use of Move 1, Move 2, and Move 3 in thesis introduction chapters written by English native speakers indicates that English native speakers followed general patterns in developing their thesis introduction chapters based on the existing theory. These Moves are realized through a number of Steps as explained in the following subchapter.

b. Steps in Thesis Introduction Chapters Written by Native Speakers 
While English native speakers employed all three Moves, they did not demonstrate all 17 Steps as suggested in CARS model by [10]. The analysis results of Steps used in thesis introduction chapters written by English native speakers are presented in Table 2.

Table 2. Steps in Thesis Introduction Chapters Written by Native Speakers

\begin{tabular}{|c|c|c|c|}
\hline Moves & Step & f & $\%$ \\
\hline \multirow[t]{4}{*}{ Move 1} & 1. Claiming centrality & 4 & $80 \%$ \\
\hline & 2. Making topic generalizations & 1 & $20 \%$ \\
\hline & 3. Defining terms & 4 & $80 \%$ \\
\hline & 4. Reviewing previous research & 0 & $0 \%$ \\
\hline \multirow[t]{4}{*}{ Move 2} & 1A. Counter Claiming & 0 & $0 \%$ \\
\hline & 1B. Indicating a gap & 1 & $20 \%$ \\
\hline & 1C. Question-Raising & 3 & $60 \%$ \\
\hline & 1D. Continuing a Tradition & 1 & $20 \%$ \\
\hline \multirow[t]{9}{*}{ Move 3} & 1. Purposes or aims & 5 & $100 \%$ \\
\hline & 2. Work carried out & 0 & $0 \%$ \\
\hline & 3. Method & 2 & $40 \%$ \\
\hline & 4. Materials or Subjects & 1 & $20 \%$ \\
\hline & 5. Findings or Results & 0 & $0 \%$ \\
\hline & 6. Product of Research & 0 & $0 \%$ \\
\hline & 7. Significance/ justification & 2 & $40 \%$ \\
\hline & 8. Thesis Structure & 0 & $0 \%$ \\
\hline & 9. Research Limitations & 1 & $20 \%$ \\
\hline
\end{tabular}


Based on Table 2, English native speakers used 11 Steps out of 17 Steps as suggested in modified CARS model [10] to realize three Moves. Move 1 (Establishing a Territory) can be manifested in four Steps; Step 1 Claiming centrality, Step 2 Making topic generalizations, Step 3 Defining terms, and Step 4 Reviewing previous research. However, the analysis results of this study did not find the use of Step 4 Reviewing previous research in Move 1 in thesis introduction chapters written by English native speakers. English native speakers, instead, dominantly used Step 1 Claiming centrality $(80 \%)$ and Step 3 Defining terms $(80 \%)$. Step 1 was used by the writes to ensure readers that the research topic is worth investigating. In order to elaborate the topic, English native speakers provided a number of relevant definitions for the readers through Step 3.

Moreover, English native speakers followed Step 2 Making topic generalizations for $20 \%$. The use of Step 1, 2, 3 Move 1 in the thesis introduction chapters can be found in the following excerpt.

Step 1: The statistical evidence of failing reading instruction within the public education system of the United States is overwhelming (National Assessment of Educational Progress [NAEP]. In addition, the social emotional implications of a low reading ability serve to complicate the situation

Step 1 (Claiming centrality) in the above example is indicated by the words overwhelming and complicate the situation. These words clearly show that the research topic is problematic and important.

Step 2: Since then, pupils all over the world have joined in the striking and protesting for climate change.

The phrase all over the world signifies that the research topic is general, occurring all over the world.

Step 3: Videos are defined as texts combining different modalities, such as words, images, sounds, and/or music (Gee and Hayes 2011:111). Thus, videos are multimodal texts. In this thesis, videos are represented by feature films, cartoons, YouTube clips, documentaries, commercials, TV shows, sitcoms (situational comedies), and shorts (films that combine both images and sounds and last between thirty seconds and fifteen minutes

Step 3 (Defining terms) is used to explain keywords of the thesis. In the above example, the thesis writer came up with several definitions of videos.

In addition, this study revealed a newly identified Step in Move 1. This Step is categorized as "Telling personal experience", which is found in two thesis introduction chapters analyzed in this study. The example of Step "Telling personal experience" is presented below.

[1] When I first read this quote, it made me think back to years of schooling and what the instruction focused on... 
[2] The choice of the topic was inspired by the researcher's personal interest in how teaching with video fits in with the communicative approach and, most importantly, how it is exercised in English classrooms....

In this Step, English native speakers attempted to present their personal experience, interest, or matter and thoroughly linked this to public concern.

Following Move 1 (Establishing a Territory) is Move 2 (Establishing a Niche). Move 2 provides writers with four options of Steps; Step 1A Counter Claiming, 1B Indicating a gap, 1C Question-Raising, and 1D Continuing a Tradition. However, the analysis results only identified the use of three Steps, i.e. Step 1B Indicating a gap (20\%), 1C Question-Raising (60\%), and 1D Continuing a Tradition (20\%).

Step 1B indicated gap of the previous studies, while Step 1D explicitly stated that further research is needed to fill the gap in Step 1B. These findings indicated that English native speakers preferred to "question" the results of previous studies, which eventually required further research. The use of Step 1B, 1C, and 1D of Move 2 can be found in the following excerpt.

Step 1B: While there have been many theoretical arguments both for and against the use of L1 in the L2 classroom, (which will be looked at in more detail in Chapters 2.2 and 2.3) there has been little research carried out which has measured the exact effects of L1 use in the classroom

Step 1B (indicating a gap) unveils that there has been little research on the topic, thus, there is a gap between the current situation and the prior studies.

Step 1C: The concept of teacher training is not straightforward to define.

In Step 1C (Questing-raising), the thesis writer probes into the vagueness of the existing concepts and studies.

Step 1D: The needs indicate that it is imperative that something is done to ensure reading and language proficient amongst our students population through a specific investigation.

Step 1D (Continuing a tradition) confirms that further research is needed.

After establishing a territory and a niche, thesis writers occupy the niche in Move 3. There are nine Steps of Move 3 provided in modified CARS model by [10], i.e. Step 1 Purposes or aims, Step 2 Work carried out, Step 3 Method, Step 4 Materials or Subjects, Step 5 Findings or Results, Step 6 Product of Research, Step 7 Significance, Step 8 Thesis Structure, and Step 9 Research Limitations. However, this study only confirms the use of five Steps, leaving four Steps out.

The analysis results identify a remarkable use of Step 1 (Purposes or Aims), which was used by all thesis writers $(100 \%)$. This proves that stating research purpose or objective is important and inevitable in composing a thesis introduction chapter. Besides Step 1, English native speakers employed Step 3 (Method) and Step 7 
(Significance) for $40 \%$. Step 4 (Materials or Subjects) and Step 9 (Limitations) were used as much as 20\%. Examples of Move 3 Steps 1, 3, 4, 7, and 9 are presented below.

Step 1: Through my research, I explored the various effects of Read 180 as it pertained to upper secondary ELL students

Step 3: This project in essence then is a form of action research.

Step 4: The research is mixed methods 3-3: it is based on interviews with four English teachers from a Norwegian lower secondary school.

Step 7: $\quad$ This project in essence then is a form of action research where the findings could have a direct impact on this particular school and the way lessons are taught.

Step 9: Such a conclusion would reinforce the researcher's own personal bias, which has come about through his own teaching experience.

The findings of this study generally seem to indicate that the rhetorical structure of the thesis introduction chapters is to some extent dependent on the cultural context in which it is written. The findings of this study are partly congruent with modified CARS model by [10].

\section{Conclusions}

This study concludes that each Introduction Chapter displays a generic pattern, comprising a series of moves \& steps. There are 3 Major Moves in the Introduction Chapter, which performs distinctive communicative functions. To realize the Moves, this study identifies 11 Steps out of 17 Steps as suggested in modified CARS model by $[10]$ and a newly identified Step in Move 1.

The findings of this study will propose practical implications for teaching English language learners or novice writers in Indonesia or in settings with similar contexts on how to compose an Introduction chapter.

\section{Acknowledgements.}

We would like to express our gratitude to:

(a) LPPM UNNES (Institute of Research \& Community Service of UNNES) that provided us with a research grant and made this research successfully conducted despite of the limitation of this study; and

(b) Yuliati a Doctorate candidate at the Univeristy of Bristol, UK for helping us get the data.

\section{References}

[1] Chek, K. L., \& Moyra, S. E. (2010). Cultural differences in the organization of research article introductions from the field of educational psychology: english and chinese. Journal of Pragmatics, 10, 2814-2825. doi:10.1016/j.pragma.2010. 03.010 
[2] Lintao, R.B. \& Erfe, J.P. (2012). A Move-Analytic Contrastive Study on the Introductions of American and Philippine Master's Theses in Architecture. I-manager's Journal on English Language Teaching, 2(1).

[3] Loan, T. T. N. \& Pramoolsook, I. (2014) Rhetorical structure of introduction chapters written by novice Vietnamese TESOL postgraduates. 3L; Language, Linguistics and Literature, The Southeast Asian Journal of English Language Studies, 20 (1), 61-74.

[4] Pujiyanti, I.A., Arsyad, S. \& Arono. (2018). Rhetorical Structure Analysis on Introduction Chapters of English Master Theses by Indonesian Postgraduate Students. Indonesian Journal of English Education, 5 (2), 143-164. doi: 10.15408/ijee.v5i2.8423

[5] Sheldon, E. (2011). Rhetorical differences in RA introductions written by English 11 and 12 and castilian Spanish 11 writers. Journal of English for Academic Purposes, 4, 238-251. doi:10.1016/ j.jeap.2011.08.004

[6] Shirani, S. \& Chalak, A. (2018). Genre Analysis of Iranian TEFL Students' Master Theses. Advances in Language and Literary Studies, 9(2), 31-37. doi: 10.7575/aiac.alls.v.9n.2p.31

[7] Wang, W. H. (2015). Claiming centrality as promotion in applied linguistics research article introductions. Journal of English for Academic Purposes, 5, 162-175. doi: 10.1016/j.jeap.2015.05.002

[8] Wuttisrisiriporn, N. (2017). Comparative Rhetorical Organization of ELT Thesis Introductions Composed by Thai and American Students. English Language Teaching, 10(12) doi: $10.5539 /$ elt.v10n12p1

[9] Yu, Z, \& Liu, M. (2016). A Contrastive Study on Generic Structure of Introduction to English Chemistry Research Articles: L1 Chinese Student Writers versus L1 English Published Writers. International Journal of English Linguistics, 6(5). doi:10.5539/ijel.v6n5p112

[10] Swales, J. M. (2004). Research genres: Exploration and applications. Cambridge: Cambridge University Press. doi: 10.1017/CBO9781139524 827

[11] Swales, J. M. (1990). Genre Analysis: English in academic settings. Cambridge: Cambridge University Press. 